\title{
Efeito da Monensina na Fermentação da Proteína de Algumas Fontes de Alimentos ${ }^{1}$
}

\author{
Rogério de Paula Lana ${ }^{2}$, Luciane Tavares da Cunha ${ }^{3}$, Arnaldo Chaer Borges ${ }^{4}$
}

RESUMO - Este trabalho foi conduzido com o objetivo de avaliar o efeito da monensina sobre a degradação protéica do farelo de soja, farelo de trigo e fubá de milho. Utilizou-se o líquido de rúmen de um novilho fistulado recebendo $40 \%$ de ração concentrada. As incubações foram feitas anaerobicamente a $39^{\circ} \mathrm{C}$, utilizando-se $100 \mathrm{mg}$ de alimentos em $14,7 \mathrm{~mL}$ de líquido ruminal e $0,3 \mathrm{~mL}$ de etanol contendo ou não monensina dissolvida ( $5 \mu \mathrm{M}$ de monensina como concentração final nos tubos de incubação). $\mathrm{O}$ farelo de soja, comparado ao farelo de trigo e fubá, apresentou maiores valores de produção de amônia, proteína microbiana, pH final e atividade específica de produção de amônia (AEPA). A maior produção de amônia foi atribuída ao alto teor de proteína e alta degradabilidade do farelo de soja e ao maior pH do meio, que aumenta a atividade de desaminação. O farelo de trigo, por sua vez, apresentou maiores valores de pH final e AEPA que o fubá de milho, demonstrando que o milho é um alimento de menor degradabilidade. A monensina diminuiu a AEPA e a degradabilidade da proteína, embora tenha sido mais efetiva em reduzir a degradação da proteína em maiores valores de pH no meio. A monensina proporciona maior eficiência na utilização da proteína pelos ruminantes, quando a dieta apresenta alta relação proteína/carboidrato fermentecível e o pH ruminal é elevado, como no caso de pastagens de gramíneas novas e leguminosas forrageiras.

Palavras-chave: amônia, fermentação, monensina, pH, proteína, rúmen

\section{Effect of Monensin on Protein Fermentation in Some Feed Sources}

ABSTRACT - This research aimed to evaluate the monensin effect on protein degradation of soybean meal, wheat middlings and corn meal. The rumen fluid was taken from a fistulated steer fed a $40 \%$ concentrate diet. The incubations were done in an anaerobic environment at $39^{\circ} \mathrm{C}$. It was used $100 \mathrm{mg}$ of each feedstuff, $14.7 \mathrm{~mL}$ of ruminal fluid and $0.3 \mathrm{~mL}$ of ethanol with or without dissolved monensin $(5 \mu \mathrm{M}$ was the final concentration). The soybean meal, compared with wheat middlings and corn meal, showed great values of ammonia production, microbial protein, final $\mathrm{pH}$ and specific activity of ammonia production (SAAP). The greatest ammonia production was due to higher protein content and high degradability of the soybean meal, associated with higher media $\mathrm{pH}$, that stimulates deamination. The wheat middlings showed greater final $\mathrm{pH}$ and SAAP than corn meal, which was a feedstuff with lower degradability. The monensin decreased the SAAP and protein degradability, although it was more effective in reducing protein degradation in higher $\mathrm{pH}$ values. Monensin provides higher efficiency of protein utilization by ruminants in diets with high protein/carbohydrate fermentation rates and high ruminal $\mathrm{pH}$, as in the case of young grasses pastures and forage legumes.

Key Words: ammonia, fermentation, monensin, $\mathrm{pH}$, protein, rumen

\section{Introdução}

Os ionóforos são antibióticos poliéteres carboxílicos (BERGEN e BATES, 1984), produzidos por várias espécies de microrganismos. Os ionóforos inibem, principalmente, as bactérias gram-positivas, uma vez que a resistência está relacionada com a presença da membrana externa, de natureza lipopolissacarídica, existente em bactérias gram-negativas (RUSSELL e STROBEL, 1988). Existem mais de 70 tipos diferentes de ionóforos, sendo os principais a monensina, lasalocida, salinomicina, narasina, tetronasina, lisocelina e laidlomicina.

A monensina foi primeiramente desenvolvida como um coccidiostato para aves e hoje é também usada para alterar a fermentação ruminal e aumentar o desempenho animal (RUSSELL, 1996). Um dos benefícios da monensina é a redução na fermentação de proteína no rúmen e, conseqüentemente, aumento na proteína disponível para o animal no intestino delgado. Isto ocorre devido à diminuição na produção de amônia ruminal, comojá demonstrado em experimentos in vitro e in vivo conduzidos por DINIUS et al. (1976) e VAN NEVEL e DEMEYER (1977).

\footnotetext{
${ }_{1}^{1}$ Parte da tese de Mestrado do segundo autor - projeto financiado pela FAPEMIG.

2 Professor do Departamento de Zootecnia - UFV - 36.571-000 - Vicosa - MG. E-mail: rlana@mail.ufv.br

${ }^{3}$ Mestre em Microbiologia Agrícola - UFV - 36.571-000 - Viçosa - MG. Bolsista do CNPq.

4 Professor do Departamento de Microbiologia - UFV - 36.571-000 - Viçosa - MG.
} 
O uso de ionóforos na ração diminui o crescimento de bactérias proteolíticas (HINO e RUSSELL, 1986) e inibe a desaminação e proteólise (RUSSELL e MARTIN, 1984), embora a desaminação seja mais afetada que a proteólise. O decréscimo da concentração de amônia ruminal vai depender da taxa de proteína/carboidrato degradável no rúmen, uma vez que, em baixas taxas, a produção de amônia ruminal e a ação da monensina são mínimas. O efeito dos ionóforos é maior em dietas à base de forrageiras ricas em proteínas, pois, sob estas condições, a taxa de degradação de proteína é muito maior que a taxa de fermentação de carboidratos e os níveis de amônia ruminal geralmente são altos (RUSSELL, 1996).

Os ruminantes alimentados com forragens apresentam pH ruminal próximo da neutralidade, mas o fornecimento de rações com alta quantidade de grãos torna a dieta altamente fermentecível, podendo diminuir o $\mathrm{pH}$ (SLYTER, 1976). A redução do pH ocorre devido ao acúmulo de ácidolático, que, por ser muito forte, resulta na diminuição quase imediata do $\mathrm{pH}$, podendo causar acidose. Monensina e lasalocida são capazes de diminuir a produção de ácido lático, contribuindo para a elevação do pH ruminal (NAGARAJA et al., 1982).

O objetivo deste trabalho foi determinar o efeito da monensina sobre a degradação da proteína de algumas fontes de alimentos pela avaliação da produção de amônia, gases, o crescimento microbiano e a atividade específica de produção de amônia, utilizando-se a técnica de incubação in vitro em líquido ruminal.

\section{Material e Métodos}

Foi utilizado o líquido de rúmen de um novilho recebendo $40 \%$ de concentrado ( $\mathrm{pH}$ inicial de 6,2). $\mathrm{O}$ líquido foi coletado 2 a 3 horas após o arraçoamento da manhâ, filtrado em quatro camadas de gaze, acondicionado em garrafa térmica hermeticamente fechada e transportado imediatamente para o laboratório. O líquido foi centrifugado a 500xg por 15 minutos em temperatura de $25^{\circ} \mathrm{C}$, para sedimentação de partículas dos alimentos e protozoários e o sobrenadante foi utilizado nas incubações.

As incubações foram feitas à temperatura de $39^{\circ} \mathrm{C}$, utilizando-se tubos Vacuntainer ${ }^{\circledR}$ com vedação hermética contendo $100 \mathrm{mg}$ de farelo de soja, farelo de trigo e fubá de milho, em tubos de incubação com $14,7 \mathrm{~mL}$ de líquido ruminal e $0,3 \mathrm{~mL}$ de etanol contendo ou não monensina $(5 \mu \mathrm{M}$ de monensina como concentração final nos tubos de incubação).

Foram desenvolvidas análises de concentração de amônia (CHANEY e MARBACH, 1962), proteína microbiana (LOWRY et al., 1951), monitoramento do pH ao longo do tempo de incubação e determinação da produção de gases.

A atividade específica de produção de amônia (AEPA), ao longo do tempo de incubação, foi determinada utilizando-se a seguinte fórmula:

$$
\text { AEPA }=\frac{\Delta \mathrm{NH}_{3} \times 1.000 .000}{\text { (proteína microbiana) } \mathrm{x} \text { (tempo de incubação) }}
$$

em que $\mathrm{AEPA}=\mathrm{nmol} \mathrm{NH}_{3} / \mathrm{mg}$ proteína microbiana/ minuto; $\Delta \mathrm{NH}_{3}=$ concentração final - inicial de amônia $(\mathrm{mM}=\mathrm{mmol} / \mathrm{L})$; proteína microbiana $=$ concentração inicial $(\mathrm{mg} / \mathrm{L})$; tempo de incubação = minutos. Para estimar a degradabilidade, determinou-se o nitrogênio utilizado na produção de amônia e crescimento microbiano em 72 horas de incubação, dividido pela quantidade de nitrogênio do alimento, conforme a seguinte fórmula:

Degradabilidade $=\underline{\operatorname{mg~N}-\mathrm{NH}_{3}+\mathrm{mg} \mathrm{N} \text {-proteína microbiana }} \times 100$ $\mathrm{mg} \mathrm{N}$-alimento

em que $\mathrm{N}-\mathrm{NH}_{3}=$ nitrogênio utilizado na produção de amônia; $\mathrm{N}$-proteína microbiana $=$ nitrogênio utilizado na síntese de proteína microbiana; $\mathrm{N}$-alimento $=$ nitrogênio presente no alimento.

As quantidades de nitrogênio presentes na amônia, na proteína microbiana e nos alimentos foram calculadas com o uso das seguintes fórmulas:

$$
\mathrm{mg} \mathrm{N}-\mathrm{NH}_{3}=\frac{\Delta \mathrm{NH}_{3}(72-0 \mathrm{~h})}{66,7} \times 14
$$

em que $\Delta \mathrm{NH}_{3}(72-0 \mathrm{~h})=$ concentração final - concentração inicial de amônia, em mmol/1000 mL ou mM; 66,7 = 1000/15 mL de líquido de rúmen; 14 = peso atômico do nitrogênio.

$$
\underset{\text { microbiana }}{\operatorname{mg~N} \text {-proteína }}=\frac{\Delta \text { proteína microbiana }(72-0 \mathrm{~h})}{66,7} \times 6,25
$$

em que $\Delta$ proteína microbiana $(72-0 \mathrm{~h})=$ concentração final - concentração inicial de proteína microbiana, em $\mathrm{mg} / \mathrm{L} ; 66,7$ = 1000/15 mL de líquido de rúmen; 6,25 = relação proteína: $\mathrm{N}$.

mg N-Alimento = alimento $(\mathrm{mg})$ x proteína bruta $(\% / 100)$ 6,25

em que 6,25 = relação proteína: $\mathrm{N}$ média dos alimentos. $\% \mathrm{~PB}=46 \%$ para o farelo de soja, $14 \%$ para o farelo 
1870 Rev. bras. zootec.

de trigo e $8,5 \%$ para o fubá de milho.

Foram obtidas equações de regressão polinomial da produção de amônia, proteína microbiana e gases, em função do tempo de incubação. As taxas de produção máxima de amônia, proteína microbiana e gases foram obtidas pela derivada primeira das equações de regressão, utilizando o tempo em que a derivada segunda se igualava a zero.

$\mathrm{O}$ experimento foi analisado em delineamento inteiramente casualizado em fatorial $3 \times 2$ (três fontes de alimento e presença ou ausência de monensina), em duplicata (dois tubos de cultura), totalizando 12 unidades experimentais. Os dados de cada unidade experimental foram obtidos pela média de duas análises laboratoriais. As análises estatísticas foram realizadas utilizando o procedimento ANOVA do MINITAB (1994), determinando-se os efeitos principais e os efeitos de interação.

Os dados foram analisados adotando-se o modelo estatístico:

$$
\mathrm{Y}_{\mathrm{ijk}}=\mu+\mathrm{Ti}+\mathrm{Nj}+\mathrm{TNij}+\mathrm{Eijk}
$$

em que $Y_{i j k}$ é a observação da unidade experimental $\mathrm{k}$, submetida ao j-ésimo nível de monensina e i-ésimo alimento; $\mu$, média geral; $\mathrm{T}_{\mathrm{i}}$, efeito do alimento $\mathrm{i}, \mathrm{i}=1$, 2 e $3 ; \mathrm{N}_{\mathrm{j}}$, efeito do nível de monensina $\mathrm{j}, \mathrm{j}=1 \mathrm{e} 2 ; \mathrm{TN}_{\mathrm{ij}}$, efeito da interação entre alimentos e níveis de monensina; $\mathrm{E}_{\mathrm{ijk}}$, erro aleatório associado a cada observação, NID $\left(0, \sigma^{2}\right)$.

Para as comparações entre os tratamentos foram utilizados os seguintes contrastes ortogonais:

$$
\begin{aligned}
& \mathrm{C} 1=2 \mathrm{~A} 1-\mathrm{A} 2-\mathrm{A} 3 \\
& \mathrm{C} 2=0+\mathrm{A} 2-\mathrm{A} 3
\end{aligned}
$$

em que $\mathrm{C} 1$ é contraste $1 ; \mathrm{C} 2$, contraste 2 ; $\mathrm{A} 1$, farelo de soja; A2, farelo de trigo; e A3, fubá de milho.

\section{Resultados e Discussão}

Os efeitos de tratamentos (fontes de alimento e monensina) sobre as curvas de produção de amônia, proteína microbiana e degradabilidade da proteína encontram-se na Figura 1 e sobre a produção de gases, $\mathrm{pH}$ do meio e atividade específica de produção de amônia, na Figura 2. Houve interação nas taxas de produção de amônia e de proteína microbiana $(\mathrm{P}<0,05)$ entre o farelo de soja $\mathrm{x}$ farelo de trigo + fubá de milho $\mathrm{x}$ monensina (Tabela 1). A monensina foi mais eficiente em reduzir a taxa de produção de amônia no alimento com alto teor de proteína, justificando sua importância em melhorar a eficiência de utilização da proteína alimentar, principalmente em dietas com alta relação proteína/carboidrato degradável no rúmen (RUSSELL, 1996).

A taxa de crescimento microbiano teve comportamento similar à taxa de produção de amônia. A população microbiana apresentou crescimento acelerado no farelo de soja, população esta provavelmente especializada na degradação de proteína, favorecendo a produção de amônia. A monensina, por sua vez, inibiu o crescimento microbiano no farelo de soja para nível semelhante ao dos outros alimentos, com ou sem monensina, provavelmente pela inibição da população que utiliza proteína como fonte de energia e nitrogênio e com alta taxa de produção de amônia (RUSSELL et al., 1988; CHEN e RUSSELL, 1989).

O efeito da monensina em reduzir a produção de amônia já foi verificado anteriormente in vitro, com uso de proteína hidrolisada (RUSSELL et al., 1988; CHEN e RUSSELL, 1989), e in vivo (YANG e RUSSELL, 1993; KRAUSE e RUSSELL, 1996). Contudo, esses autores não avaliaram o comportamento da monensina em diferentes fontes de alimento.

Tabela 1 - Efeitos da monensina $(5 \mu \mathrm{M})$ e de fontes de alimento (100 mg) sobre as taxas de produção de amônia e proteína microbiana em $15 \mathrm{~mL}$ de líquido de rúmen

\begin{tabular}{|c|c|c|c|c|c|c|c|c|c|c|c|c|}
\hline & \multicolumn{3}{|c|}{$\begin{array}{l}\text { Sem monensina } \\
\text { Without monensin }\end{array}$} & \multicolumn{3}{|c|}{$\begin{array}{c}\text { Com monensina } \\
\text { With monensin }\end{array}$} & \multirow[b]{2}{*}{ EP } & \multicolumn{5}{|c|}{$\begin{array}{c}\text { Significância }(\mathrm{P}=) \\
\text { Significance }\end{array}$} \\
\hline & FS & FT & FM & FS & $\begin{array}{l}\text { FT } \\
\end{array}$ & $\overline{F M}$ & & $\mathrm{Ll}$ & $\mathrm{L} 2$ & $\mathrm{M}$ & L1xM & $\overline{\mathrm{L} 2 \mathrm{xM}}$ \\
\hline $\begin{array}{l}\mathrm{NH}_{3}\left(\mathrm{mM} / \mathrm{h}^{1}\right) \\
\text { Proteína microbial }\end{array}$ & $\begin{array}{l}0,90 \\
42,4\end{array}$ & $\begin{array}{l}0,24 \\
23,7\end{array}$ & $\begin{array}{l}0,12 \\
12,0\end{array}$ & $\begin{array}{l}0,11 \\
14,2\end{array}$ & $\begin{array}{l}0,13 \\
14,4\end{array}$ & $\begin{array}{l}0,15 \\
19,9\end{array}$ & $\begin{array}{l}0,12 \\
5,85\end{array}$ & $\begin{array}{l}0,00 \\
0,00\end{array}$ & $\begin{array}{l}1,00 \\
0,78\end{array}$ & $\begin{array}{l}0,04 \\
0,45\end{array}$ & $\begin{array}{l}0,01 \\
0,04\end{array}$ & $\begin{array}{l}0,85 \\
0,78\end{array}$ \\
\hline
\end{tabular}

Table 1 - Effects of monensin $(5 \mu \mathrm{M})$ and feed sources $(100 \mathrm{mg})$ on rates of ammonia and microbial protein production in $15 \mathrm{~mL}$ of rumen fluid

Microbial protein $\mathrm{mg} / \mathrm{L} / \mathrm{h}^{2}$

FS = farelo de soja; FT = farelo de trigo; FM = fubá de milho; EP = erro-padrão da média; $L 1$ = farelo de soja vs farelo de trigo e fubá de milho; $\mathrm{L} 2$ = farelo de trigo vs fubá de milho; $\mathrm{M}=$ monensina.

$F S=$ Soybean meal; $F T=$ wheat middlings; $F M=$ corn meal; $E P=$ standard error of mean; $L 1=$ soybean meal vs wheat middlings and corn meal; $L 2=$ wheat middlings vs corn meal; $M=$ monensin.

1,2 Dados obtidos pela derivada primeira da equação de regressão utilizando o tempo em que a derivada segunda se igualava a zero.

1,2 Data obtained by the derived regression equation by using the time that nuled the secondary derived equation. 
LANA et al.
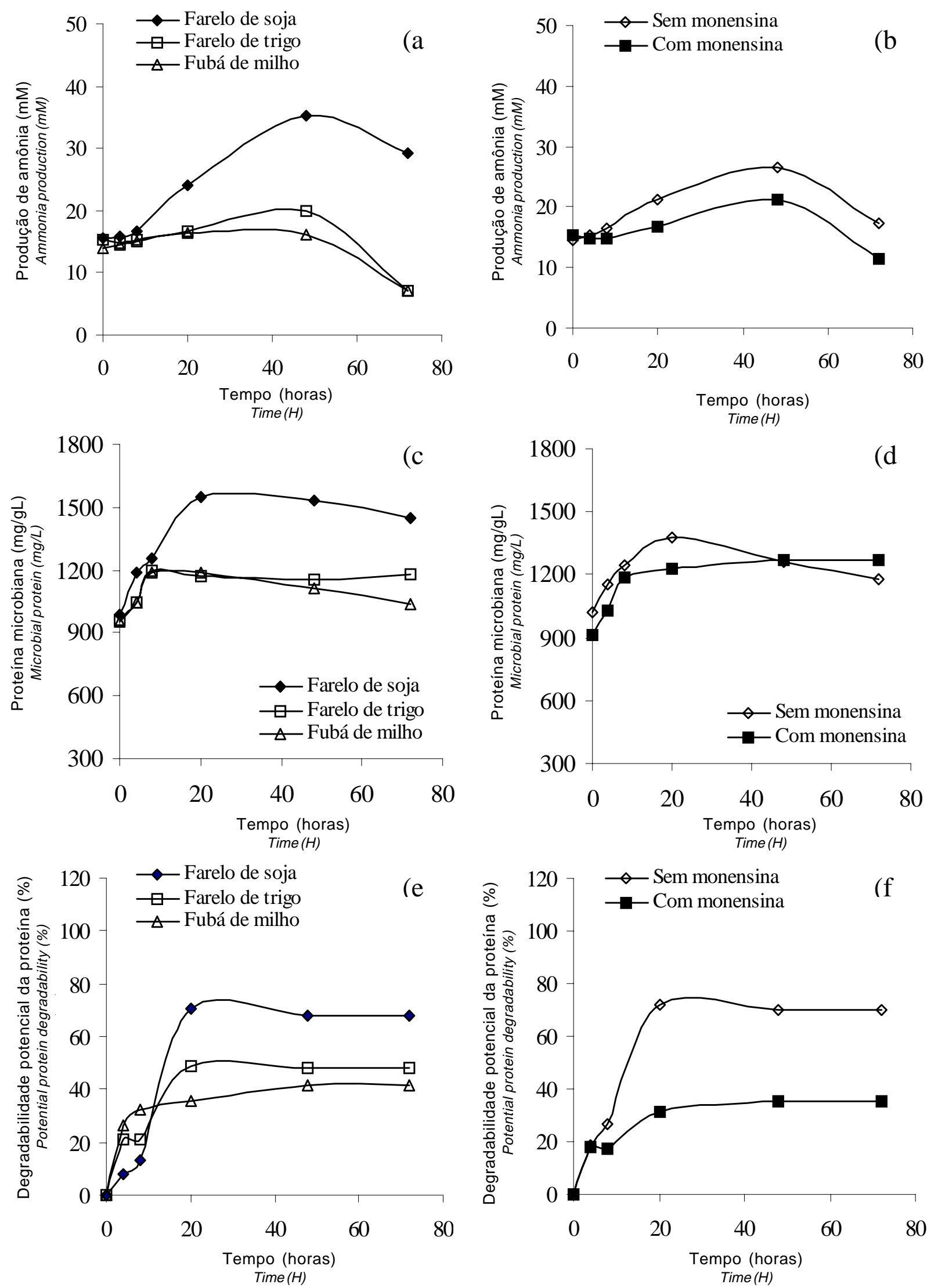

Figura 1 - Efeitos de fontes de alimento (100 mg) (farelo de soja, $\bullet$; farelo de trigo, $\mathbf{m}$; e fubá de milho, $\mathbf{\Delta})$ e monensina $(5 \mu \mathrm{M})$ sobre a produção de amônia $(a, b)$, proteína microbiana $(c, d)$ e degradabilidade da proteína (e, f) em incubações contendo $15 \mathrm{~mL}$ de líquido de rúmen. Cada ponto corresponde à média de 8 (alimentos) ou 12 (monensina) observações.

Figure 1 - Effects of feed sources (100 mg) (soybean meal, $\bullet$; wheat middlings, $\mathbf{a}$; and corn meal, $\mathbf{\Delta})$ and monensin (5 $\mu \mathrm{M}$; closed symbol) on ammonia production $(a, b)$, microbial protein $(c, d)$ and protein degradation $(e, f)$ over time in incubations containing $15 \mathrm{~mL}$ of rumen fluid. Each point is the mean of 8 (feed source) or 12 (monensin) observations. 
1872 Rev. bras. zootec.

As análises estatísticas dos dados apresentados nas Figuras 1 e 2, às 72 horas de incubação, encontram-se na Tabela 2. Não houve efeito de interação $(\mathrm{P}>0,05)$ entre alimento e monensina, sendo reportados somente os efeitos principais. O farelo de soja, comparado ao farelo de trigo e fubá, apresentou $(\mathrm{P}<0,05)$ maiores valores de produção de amônia, proteína microbiana, $\mathrm{pH}$ final e atividade específica de produção de amônia (AEPA). O farelo de trigo, por sua vez, apresentou maiores valores de $\mathrm{pH}$ final e AEPA que o fubá de milho $(\mathrm{P}<0,05)$, demonstrando ser o fubá de milho um alimento de menor degradabilidade e mais resistente à ação dos microrganismos.

A monensina tendeu a diminuir $(\mathrm{P}<0,10)$ a produção e taxa de produção de gases e reduziu a AEPA e a degradabilidade da proteína $(\mathrm{P}<0,05)$, demonstrando que o ionóforo é um potente inibidor da atividade degradativa das bactérias, principalmente bactérias proteolíticas como $B$. fibrisolvens, $F$. succinogenes e S. bovis (SLYTER, 1976). A maior produção de amônia foi atribuída ao alto teor de proteína e alta degradabilidade do farelo de soja e ao maior $\mathrm{pH}$ do meio, que aumenta a atividade de desaminação. (ERFLE et al., 1982; LANA et al., 1998).

$\mathrm{O}$ efeito da monensina sobre a produção de gases também foi observado por BARTLEY et al. (1979) e SCHELLING (1984). A redução na produção de gases é atribuída à diminuição da relação acetato/propionato no processo de fermentação, uma vez que a síntese de ácido acético favorece a produção de gases (RUSSELL e STROBEL, 1989).

Foram observados maiores valores de coeficientes de correlações $(0,56$ a 0,72$)$ do contraste L1 (farelo de soja vs farelo de trigo e fubá de milho) sobre a produção de amônia (mM, mM/hora, AEPA) (Tabela 3), demonstrando a maior degradabilidade do farelo de soja em relação aos outros alimentos. A monensina, por sua vez, apresentou menores valores de coeficientes de correlações $(-0,20$ a $-0,34)$ com a produção de amônia em relação ao $\mathrm{pH}$, que foi o parâmetro que apresentou maiores correlações com a produção de amônia $(0,60$ a 0,81$)$ (Tabela 3$)$.

A monensina interagiu com o $\mathrm{pH}$ sobre a degradabilidade da proteína $(-0,47)(\mathrm{P}<0,05)$, indicando que o ionóforo foi mais efetivo em reduzir a degradação em maiores valores de $\mathrm{pH}$ no meio (Figura 3). A inibição da monensina sobre a degradação da proteína foi reduzida em líquido ruminal com maior acidez, mostrando-se similar ao efeito do $\mathrm{pH}$, provavelmente pela inibição de populações de bactérias desaminadoras de aminoácidos. A

Tabela 2 - Efeitos de fontes de alimento (100mg) e monensina $(5 \mu \mathrm{M})$ sobre a produção de amônia (72-0 horas), proteína microbiana (72 horas), produção (72 horas) e taxa de produção de gases, pH, atividade específica de produção de amônia (AEPA, 72 horas) e degradabilidade da proteína (D) em $15 \mathrm{~mL}$ de líquido ruminal

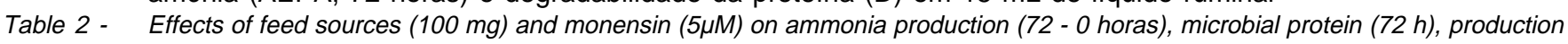
$(72 \mathrm{~h})$ and rate of gas production, $\mathrm{pH}$, specific activity of ammonia production (AEPA, $72 \mathrm{~h}$ ) and protein degradation (D) in $15 \mathrm{~mL}$ of rumen fluid

\begin{tabular}{|c|c|c|c|c|c|c|c|c|c|c|c|}
\hline & \multicolumn{3}{|c|}{$\begin{array}{l}\text { Alimento } \\
\text { Feed source }\end{array}$} & \multicolumn{2}{|c|}{$\begin{array}{c}\text { Com Monensina } \\
\text { Monensin }\end{array}$} & \multirow[b]{2}{*}{$\mathrm{EP}$} & \multicolumn{5}{|c|}{$\begin{array}{c}\text { Significância (Significance) } \\
\qquad(\mathrm{P}=)\end{array}$} \\
\hline & FS & FT & FM & $\begin{array}{l}\text { Sem } \\
\text { (w/out })\end{array}$ & $\begin{array}{l}\text { Com } \\
\text { (with) }\end{array}$ & & $\mathrm{L} 1$ & $\mathrm{~L} 2$ & M & L1xM & L2xM \\
\hline $\mathrm{NH}_{3}, \mathrm{mM}$ & 29,29 & 7,15 & 6,99 & 17,37 & 11,59 & 5,25 & 0,00 & 0,81 & 0,19 & 0,13 & 0,71 \\
\hline $\begin{array}{l}\text { Proteína } \\
\text { mic., mg/L } \\
\text { Microbial protein }\end{array}$ & 1451 & 1177 & 1042 & 1178 & 1268 & 164,3 & 0,02 & 0,52 & 0,51 & 0,29 & 0,92 \\
\hline Gases, mL & 8,25 & 11,6 & 10,2 & 11,3 & 8,80 & 1,710 & 0,27 & 0,94 & 0,09 & 0,86 & 0,36 \\
\hline Gases, $\mathrm{mL} / \mathrm{h}^{1}$ & 0,24 & 0,29 & 0,32 & 0,32 & 0,24 & 0,049 & 0,36 & 0,97 & 0,07 & 0,83 & 0,52 \\
\hline $\mathrm{pH}$ final & 6,08 & 5,64 & 5,00 & 5,59 & 5,56 & 0,132 & 0,00 & 0,00 & 0,84 & 0,83 & 0,47 \\
\hline AEPA & 3,73 & 2,22 & 0,54 & 2,84 & 1,48 & 0,721 & 0,00 & 0,04 & 0,03 & 0,21 & 0,39 \\
\hline $\mathrm{D}(\%)$ & 67,9 & 48,2 & 41,6 & 69,9 & 35,2 & 16,39 & 0,09 & 0,73 & 0,02 & 0,39 & 0,92 \\
\hline
\end{tabular}

$\overline{\mathrm{FS}}$ = Farelo de soja; FT = farelo de trigo; FM = fubá de milho; EP = erro padrão da média; L1 = farelo de soja vs farelo de trigo e fubá de milho; $\mathrm{L} 2$ =farelo de trigo vs fubá de milho; $M$ = monensina; $D=$ degradabilidade da proteína.

1 Dados obtidos pela derivada primeira da equação de regressão utilizando o tempo em que a derivada segunda se igualava a zero.

$F S=$ Soybean meal; $F T=$ wheat middlings; $F M=$ corn meal; $E P=$ standard error of mean; $L 1$ = soybean meal vs wheat middlings and corn meal; $L 2=$ wheat middlings vs corn meal; $M=$ monensin; $D=$ protein degradation.

1 Data obtained by the derived regression equation by using the time that nuled the secondary derived equation. 
LANA et al.
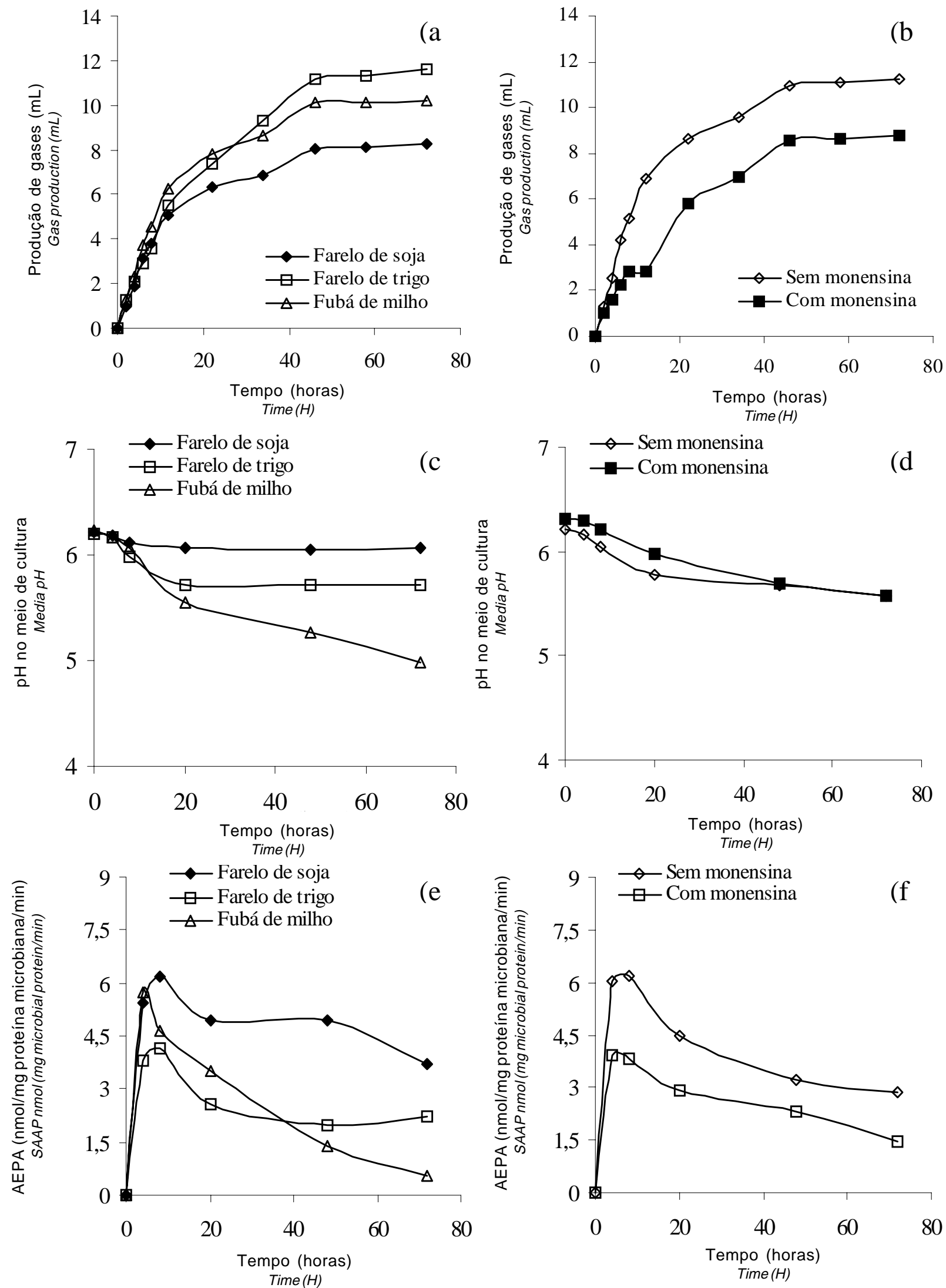

Figura 2 - Efeitos de fontes de alimento (100 mg) (farelo de soja, $\bullet$; farelo de trigo, $\mathbf{m}$; e fubá de milho, $\mathbf{\Delta}$ ) e monensina (5 $\mu \mathrm{M})$ sobre a produção de gases $(a, b)$, acidez (c, d) e atividade específica de produção de amônia (AEPA) (e, f), em incubações contendo $15 \mathrm{~mL}$ de líquido de rúmen. Cada ponto corresponde à média de 8 (alimentos) ou 12 (monensina) observações.

Figure 2 - Effects of food source (100 mg) (soybean meal, ; wheat middlings, $\mathbf{n}$; and corn meal, $\mathbf{\Delta}$ ) and monensin (5 $\mu$ M; square symbol) on gas production $(a, b)$, acidity $(c, d)$ and specific activity of ammonia production $(S A A P)(e, f)$ over time in incubations containing $15 \mathrm{~mL}$ of rumen fluid. Each point is the mean of 8 (feed source) or 12 (monensin) observations. 
1874 Rev. bras. zootec.

Tabela 3 - Coeficientes de correlações lineares entre alguns parâmetros provenientes da incubação de microrganismos ruminais em um meio contendo alimentos $(100 \mathrm{mg})$ e monensina $(5 \mu \mathrm{M})$ em $15 \mathrm{~mL}$ de líquido de rúmen, após 72 horas de incubação

Table 3 - Coefficients of linear correlation among some parameters from the incubation of $15 \mathrm{~mL}$ of rumen fluid with $100 \mathrm{mg}$ of some feed sources and monensin $(5 \mu M)$ in 72 hours

\begin{tabular}{|c|c|c|c|c|c|c|c|c|c|c|}
\hline & L1 & $\mathrm{L} 2$ & M & $\mathrm{pH}$ final & $\mathrm{pH} \times \mathrm{M}$ & $\begin{array}{c}\mathrm{NH}_{3} \\
\mathrm{mM}\end{array}$ & $\begin{array}{l}\mathrm{NH}_{3}, \\
\mathrm{mM} / \mathrm{h}\end{array}$ & AEPA & $\begin{array}{l}\text { Ptn. } \\
\text { mic., } \\
\text { mg/L }\end{array}$ & $\begin{array}{l}\text { Ptn. } \\
\text { mic., } \\
\text { mg/l/h }\end{array}$ \\
\hline$\overline{\mathrm{L} 2}$ & 0,00 & & & & & & & & & \\
\hline M & 0,00 & 0,00 & & & & & & & & \\
\hline $\mathrm{pH}$ final & 0,72 & 0,52 & $-0,02$ & & & & & & & \\
\hline $\mathrm{pH} \times \mathrm{M}$ & 0,07 & 0,04 & 0,99 & 0,06 & & & & & & \\
\hline $\mathrm{NH}_{3}, \mathrm{mM}$ & 0,72 & $-0,00$ & $-0,20$ & 0,69 & 0,16 & & & & & \\
\hline $\mathrm{NH}_{3}, \mathrm{mM} / \mathrm{h}$ & 0,59 & $-0,03$ & $-0,31$ & 0,60 & $-0,29$ & 0,91 & & & & \\
\hline AEPA & 0,56 & 0,35 & $-0,34$ & 0,81 & $-0,30$ & 0,77 & 0,80 & & & \\
\hline Ptn. mic., mg/l & 0,47 & $-0,16$ & 0,13 & 0,14 & 0,13 & 0,41 & 0,27 & $-0,04$ & & \\
\hline Ptn. micr., mg/l/h & 0,59 & $-0,11$ & $-0,13$ & 0,41 & 0,12 & 0,77 & 0,72 & 0,51 & 0,60 & \\
\hline Degr.ptn. $(\%)$ & 0,31 & 0,08 & $-0,48$ & 0,49 & $-0,47$ & 0,70 & 0,79 & 0,76 & 0,08 & 0,56 \\
\hline
\end{tabular}

interação entre a acidez e monensina sobre a produção de amônia pode ser a explicação do maior efeito dessa substância sobre o desempenho de animais em pastejo e, conseqüentemente, sobre a eficiência de utilização do nitrogênio alimentar, em comparação áqueles em confinamento (GOODRICH et al., 1984).

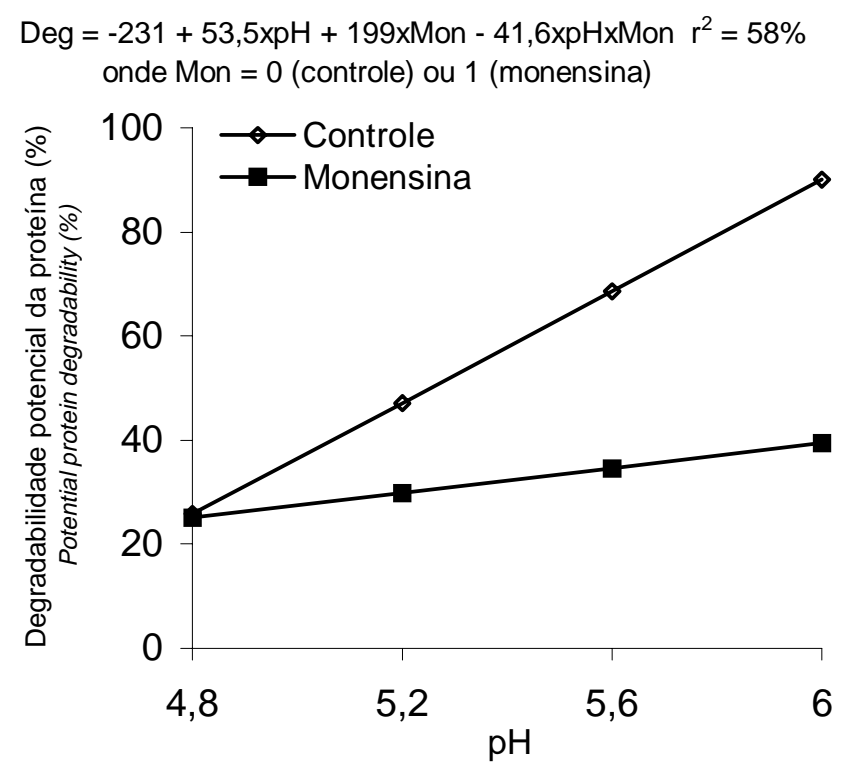

Figura 3 - Efeitos de monensina $(5 \mu \mathrm{M})$ sobre a degradabilidade da proteína dos alimentos em incubações contendo $15 \mathrm{~mL}$ de líquido de rúmen em diferentes valores de $\mathrm{pH}$.

Figure 3 - Effects of monensin $(5 \mu \mathrm{M})$ on feed protein degradation in incubations containing $15 \mathrm{~mL}$ of rumen fluid in different $\mathrm{pH}$ values.
$\mathrm{O}$ efeito da monensina sobre a inibição das bactérias gram-positivas, fermentadoras vigorosas de aminoácidos, entre elas Peptostreptococcus anaerobius, Clostridium sticklandii e Clostridium aminophilum, foi demonstrado in vitro por RUSSELL et al. (1988) e CHEN e RUSSELL (1989) e sobre as bactérias $P$. anaerobius e $C$. sticklandii in vivo, por KRAUSE e RUSSELL (1996). O efeito inibitório da acidez do líquido ruminal sobre as $P$. anaerobius e $C$. sticklandii foi observado in vitro (CHEN e RUSSELL, 1988; CHEN e RUSSELL, 1989), em que a inibição foi mais expressiva em valores de $\mathrm{pH}$ menor que 6,0 .

\section{Conclusões}

Os ionóforos proporcionam maior eficiência na utilização da proteína pelos animais ruminantes, quando a dieta apresenta alta relação proteína/ carboidrato fermentecível e o $\mathrm{pH}$ ruminal é elevado, como no caso de animais sob alimentação de volumosos de boa qualidade.

\section{Referências Bibliográficas}

BARTLEY, E.E., HEROD, E.L., BECHTLE, R.M. et al. 1979. Effect of monensin, lasalocid, or a new polyether antibiotic with and without niacin or amicloral on rumen fermentation in vitro and on heifer growth and feed efficiency. J. Anim. Sci., 49:1066-1075.

BERGEN, W.G., BATES, D.B. 1984. Ionophores: their effect on production efficiency and mode of action. J. Anim. Sci., 
58:1465-1483.

CHANEY, A.L., MARBACH, E.P. 1962. Modified reagents for determination of urea and ammonia. Clin. Chem., 8:130-132.

CHEN, G., RUSSELL, J.B. 1988. Fermentation of peptides and amino acids by a monensin-sensitive ruminal peptostreptpcoccus. Appl. Environ. Microbiol., 54:2742-2749.

CHEN, G., RUSSELL, J.B. 1989. More monensin-sensitive, ammonia-producing bacteria from the rumen. Appl. Environ. Microbiol., 55:1052-1057.

DINIUS, D.A., SIMPSON, M.E., MARSH, P.B. 1976. Effect of monensin fed with forage on digestion and the ruminal ecosystem of steers. J. Anim. Sci., 42:229-234.

ERFLE, J.D., BOILA, R.J., TEATHER, R.M. et al. 1982. Effect of $\mathrm{pH}$ on fermentation characteristics and protein degradation by rumen microorganisms in vitro. J. Dairy Sci., 65:1457-1464.

GOODRICH, R.D., GARRETT, J.E., GAST, D.R. 1984. Influence of monensina on the performance of cattle. J. Anim. Sci., 58:1484-1498.

HINO, T., RUSSELL, J.B. 1986. Relative contributions of ruminal bacteria and protozoa to the degradation of protein in vitro. J. Anim. Sci., 64:261-270.

KRAUSE, D.O., RUSSELL, J.B. 1996. An rRNA approach for assessing the role of obligate amino acid-fermenting bacteria in ruminal amino acid degradation. Appl. Environ. Microbiol., 62:815-821

LANA, R.P., RUSSELL, J.B., AMBURGH, M.E.V. 1998. The role of $\mathrm{pH}$ in regulating ruminal methane and ammonia production. J. Anim. Sci., 76:2190-2196.

LOWRY, O.H., ROSEBROUGH, N.J., FARR, A.L. et al. 1951. Protein measurement with the Folin phenol reagent. J. Biol. Chem., 193:265-275.

MINITAB. 1994. Minitab ${ }^{\circledR}$ Reference Manual, PC Version, Release 10.1. Minitab Inc., State College, PA.

NAGARAJA, T.G., AVERY, T.B., BARTLEY, E.E. et al. 1982. Effect of lasalocid, monensin, or thiopeptin on lactic acidosis in cattle. J. Anim. Sci., 54:649-658.
1875

RUSSELL, J.B. Bacteria: mechanisms of ionophore action in ruminal bacteria. In: SYMPOSIUM SCIENTIFIC UPDATE ON RUMENSIN/TYLAN FOR THE PROFESSIONAL FEEDLOT CONSULTANT, 1996, Amarillo, TX, Indianapolis, IN, Proceedings... Indianapolis: Elanco Animal Health, 1996. p.E1-E19.

RUSSELL, J.B., MARTIN, S.A. 1984. Effects of various methane inhibitors on the fermentation of amino acids by mixed rumen micoorganisms in vitro. J. Anim. Sci., 59:1329-1338.

RUSSELL, J.B., STROBEL, H.J. 1988. Effects of additives on in vitro ruminal fermentation: a comparison of monensin and bacitracin, another Gram-positive antibiotic. J. Anim. Sci., 66:552-558.

RUSSELL, J.B., STROBEL, H.J. 1989. Mini-review: The effect of ionophores on ruminal fermentation. Appl. Environ. Microbiol., 55:1-6.

RUSSELL, J.B., STROBEL,H.J., CHEN,G. 1988. The enrichment and isolation of a ruminal bacterium with a very high specific activity of ammonia production. Appl. Environ. Microbiol., 54:872-877.

SCHELLING, G.T. 1984. Monensin mode of action in the rumen. J. Anim. Sci., 58:1518-1527.

SLYTER, L.L. 1976. Influence of acidosis on rumen function. J. Anim. Sci., 43:910-929.

VAN NEVEL, C.J., DEMEYER, D.I. 1977. Effect of monensin on rumen metabolism in vitro. Appl. Environ. Microbiol., 34:251-257.

YANG, C.M.J., RUSSELL, J.B. 1993. Effect of monensin on the specific activity of ammonia production by ruminal bacteria and disappearance of amino nitrogen from the rumen. Appl. Environ. Microbiol., 59:3250-3254.

Recebido em: 10/12/99

Aceito em: 17/04/00 